\title{
ANATOMICAL VARIATIONS OF SPHENOIDAL INTER-SINUS SEPTA IN TERMS OF NUMBER AND ATTACHMENTS - A CT FINDING
}

\author{
Sushil Kumar Kashyap ${ }^{1}$, Jagdish Prasad Purohit ${ }^{2}$, Siva Selvaraj3, Vineet Kumar ${ }^{4}$, Sylveena Moshahary5, Chandra Bhan ${ }^{6}$, Ishan Dixit ${ }^{7}$
}

${ }^{1}$ Associate Professor, Department of ENT, MLB Medical College, Jhansi, Uttar Pradesh.

2 Professor and HOD, Department of ENT, MLB Medical College, Jhansi, Uttar Pradesh.

3Junior Resident, Department of ENT, MLB Medical College, Jhansi, Uttar Pradesh.

4Junior Resident, Department of ENT, MLB Medical College, Jhansi, Uttar Pradesh.

5Junior Resident, Department of ENT, MLB Medical College, Jhansi, Uttar Pradesh.

${ }^{6}$ Senior Resident, Department of ENT, MLB Medical College, Jhansi, Uttar Pradesh.

7 Junior Resident, Department of ENT, MLB Medical College, Jhansi, Uttar Pradesh.

\section{ABSTRACT}

\section{BACKGROUND}

Sphenoid sinus is an important structure located in the body of the sphenoid bone. It is separated from critical surrounding structures like optic nerve and chiasm, cavernous sinus, pituitary gland and internal carotid artery by a thin bony lamella. Because of its location and close relation to these important anatomical structures, diagnosis and treatment of sphenoid sinus pathologies are very challenging. In the era of endoscopic approach to the sphenoid sinus and skull base, the detailed knowledge of anatomy of sphenoid sinus and its closely related structures is mandatory.

The objective of this study is, in this study we concentrated on the variations in the anatomy of sphenoid septa in terms of number and attachment to the nearby structures with the help of computed tomography.

\section{MATERIALS AND METHODS}

Retrospective analysis of the computed tomography of the PNS of 80 patients who came to the OPD of Department of ENT, Head and Neck Surgery, MLB Medical College, Jhansi with the complaints of headache, nasal discharge and nasal blockade was carried out. Anatomy of the sphenoid sinus and the variations in its anatomy were noted.

\section{RESULT}

With this study, we found that there are numerous anatomical variations in the sphenoid septum in its number and attachment. Commonest type being single complete septum and commonest attachment was to carotid artery.

\section{CONCLUSION}

Knowledge of sphenoid sinus anatomy for every single patient before sphenoid surgery is paramount and should be obtained with the help of pre-operative computed tomographic study of the paranasal sinuses.

\section{KEYWORDS}

Sphenoid Sinus, Computed Tomography, Anatomical Variations, Endoscopic Sinus Surgery, Skull Base, Internal Carotid Artery, Optic Nerve, Pituitary.

HOW TO CITE THIS ARTICLE: Kashyap SK, Purohit JP, Selvaraj S, et al. Anatomical variations of sphenoidal inter-sinus septa in terms of number and attachments - a CT finding. J. Evolution Med. Dent. Sci. 2017;6(12):955-959, DOI: 10.14260/Jemds/2017/204

\section{BACKGROUND}

The sphenoid sinus is recognisable at around the third intrauterine month as an evagination from the sphenoethmoidal recess and can be seen as a small cavity at the time of birth. At the age of four, pneumatisation of the sphenoid bone progresses and by seven years it reaches the floor of the sella turcica in most of the cases.[1,2] Pneumatisation is said to progress at a rate of $0.25 \mathrm{~mm}$ each year from the age of four years, but this is not constant.[1] In adults, degree of pneumatisation and the septum vary greatly, asymmetry being the rule rather than the exception.[1,3] In rare cases, internal carotid artery, optic nerve, V2 and the vidian nerve can be dehiscent in the walls of the sphenoid sinus with almost no bony wall. $[4,5,6]$

Financial or Other, Competing Interest: None.

Submission 21-12-2016, Peer Review 19-01-2017,

Acceptance 23-01-2017, Published 09-02-2017.

Corresponding Author:

Dr. Sushil Kumar Kashyap,

Associate Professor,

MLB Medical College,

Jhansi, Uttar Pradesh.

E-mail: selvarajk.siva@gmail.com

DOI: $10.14260 /$ jemds $/ 2017 / 204$

\section{(c) (i) $९$}

Sphenoid sinus is considered to have the most variations in comparison to other sinuses in terms of degree and type of pneumatisation and inter-sinus septa and surrounding structures.

The sphenoid sinus is located in the body of the sphenoid bone and is divided by inter-sinus septa into two or more compartments. Superiorly, it is related to sella turcica, the internal carotid artery in its lateral walls, the optic nerve superolaterally and the Vidian canal in lateral click here to view linked References aspect of its floor. Its ostium is located medially in the superior portion of the anterior sinus wall and communicates with the sphenoethmoidal recess and the posterior portion of the superior meatus. The sphenoethmoidal recess is located lateral to the nasal septum and although best demonstrated in the sagittal and axial planes, may also be seen on coronal images. The thin intersinus septum separates the sinus into two in most of the cases, but in some cases this septa may be more than one; complete or incomplete separating the sinus into more than two compartments or it may be absent also.[7,8] The intersphenoid septum is often deviated to one side and may be attached to the bony wall covering the nearby structures as mentioned above. [9] Hence, these structures may be injured when the septum is avulsed during surgery. 
The knowledge of sphenoid septal variations in terms of numbers and attachments to important prominence on lateral or posterior wall of sphenoid sinus is the key point for a safe sphenoid or trans-sphenoidal skull base surgery.[10]

CT scan is the gold standard for the visualisation of sphenoidal sinus variations including the inter-sinus septa and its attachments. In our study, we investigated the variations in the sphenoid inter-sinus septa in terms of number and its attachments to various important prominences in the sphenoid sinus wall. Our aim was to determine these anatomical variations of inter-sphenoid septum for safe and successful surgery of the sphenoid sinus and skull base.

\section{Objective}

To determine the anatomical variations in the septum of sphenoid sinus in terms of number, position and attachments with the help of NCCT paranasal sinus of the patients presenting to OPD, Department of ENT and Head and Neck Surgery, M. L. B Medical College, Jhansi, Uttar Pradesh, India.

\section{MATERIALS AND METHODS}

The study was carried out in 80 patients who came to the OPD of Department of ENT, Head and Neck Surgery, MLB Medical College, Jhansi with the complaints of headache, nasal discharge and nasal blockade. All the patients underwent complete history taking and detailed examination including anterior and posterior rhinoscopy. They also underwent x-ray, PNS waters' view, nasal endoscopy and CT scan of paranasal sinuses to evaluate the status of disease and anatomy of PNS.

Patients who had previously undergone endoscopic sinus surgery were excluded from our study. Computerised tomography was done in axial and coronal sections with the neck slightly extended when the patient was positioned supine in the CT gantry and $2 \mathrm{~mm}$ slice thickness was used. Sphenoid sinus was studied for the number of compartments as separated by one or more than one septum or absent septum and the symmetry or asymmetry of the compartments and also for the attachment of the septum.

\section{RESULTS}

Out of the 80 patients taken for the study, 53 were males and 27 were females [Figure 6], ranging from age 14 years to 60 years. NCCT of paranasal sinuses in axial and coronal sections were analysed.

Total six types of sphenoid septal variations [Figure 7] regarding the number were found namely.

1. Single complete septum [Figure 1] dividing the sinus into 2 compartments ( $n=42,52.5 \%$ ).

2. Single incomplete [Figure 2] septum $(n=12,15 \%)$.

3. Double complete [Figure 3] septa $(n=4 ; 5 \%)$.

4. Double septa of which one is complete and the other one incomplete [Figure 4] $(\mathrm{n}=13 ; 16.25 \%)$.

5. Triple septa $(n=5 ; 6.25 \%)$.

6. Absent septum [Figure 5] $(\mathrm{n}=4 ; 5 \%)$.

Five various types of attachment of the sphenoid sinus septa to wall [Figure 8] are identified in the study and the observations are mentioned below -

1. Carotid $(n=28 ; 35 \%)$.
2. Sella ( $\mathrm{n}=21 ; 26.25 \%)$.

3. Lateral wall of the sinus $(n=10 ; 12.5 \%)$.

4. Optic nerve $(n=2 ; 2.5 \%)$.

5. To both sella and carotid ( $\mathrm{n}=9 ; 11.25 \%)$.

6. To both carotid and lateral wall $(\mathrm{n}=5 ; 6.25 \%)$.

7. To sella, carotid and lateral wall $(n=1 ; 1.25 \%)$.

In summary there were single septum in $81.25 \%$, double septa in $12.5 \%$ and no septum in $6.25 \%$ of the cases.

\begin{tabular}{|c|c|}
\hline Male & Female \\
\hline 53 & 27 \\
\hline \multicolumn{2}{|c|}{ Table 1. Showing Sex Distribution of the Patients } \\
\hline
\end{tabular}

\begin{tabular}{|c|c|c|}
\hline Type & No. of Cases & Percentage \\
\hline Single Complete Septum & 42 & $52.5 \%$ \\
\hline Single Incomplete Septum & 12 & $15 \%$ \\
\hline Double Complete Septa & 4 & $5 \%$ \\
\hline $\begin{array}{l}\text { Double Complete + Incomplete } \\
\text { Septa }\end{array}$ & 13 & $16.25 \%$ \\
\hline Triple Septa & 5 & $6.25 \%$ \\
\hline No Septum & 4 & $5 \%$ \\
\hline \multicolumn{3}{|c|}{$\begin{array}{l}\text { Table 2. Showing the Variations of Septa } \\
\text { and Sphenoid Compartments }\end{array}$} \\
\hline
\end{tabular}

\begin{tabular}{|c|c|c|}
\hline Attachment of the Septum & No. of Cases & Percentage \\
\hline Carotid & 28 & $35 \%$ \\
\hline Sella & 21 & $26.25 \%$ \\
\hline Lateral Wall & 10 & $12.5 \%$ \\
\hline Optic Nerve & 2 & $2.5 \%$ \\
\hline Sella and Carotid & 9 & $11.25 \%$ \\
\hline Carotid and Lateral Wall & 5 & $6.25 \%$ \\
\hline $\begin{array}{c}\text { Sella, Carotid and Lateral } \\
\text { Wall }\end{array}$ & 1 & $1.25 \%$ \\
\hline No Septum & 4 & $5 \%$ \\
\hline \multicolumn{3}{|c|}{$\begin{array}{l}\text { Table 3. Showing the Variations in } \\
\text { the Attachment of Sphenoid Septum }\end{array}$} \\
\hline
\end{tabular}

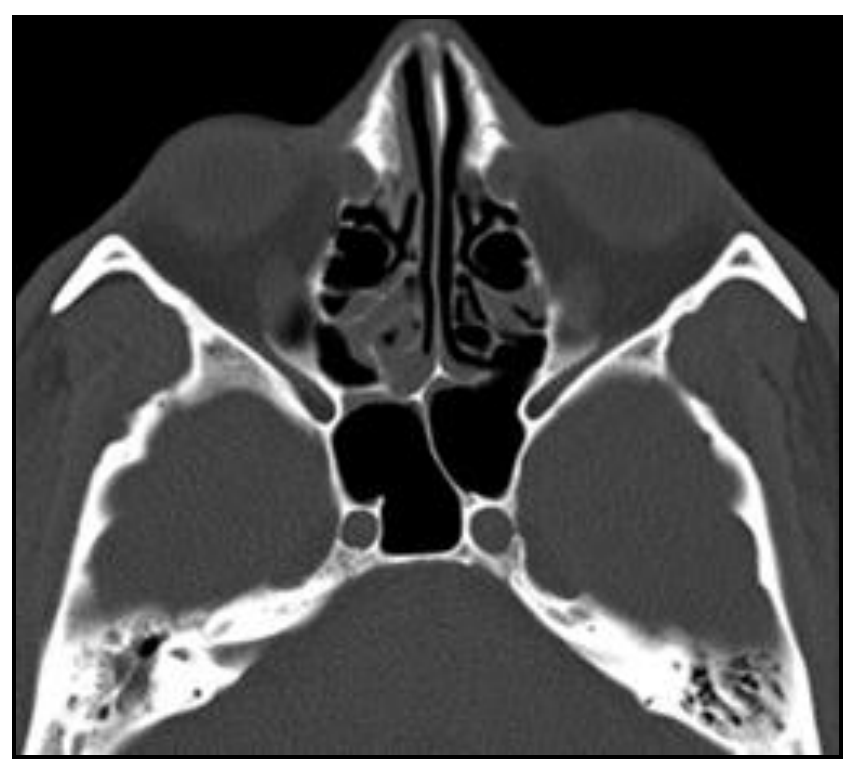

Figure 1. CT Scan showing a Single Complete Sphenoidal Septum 


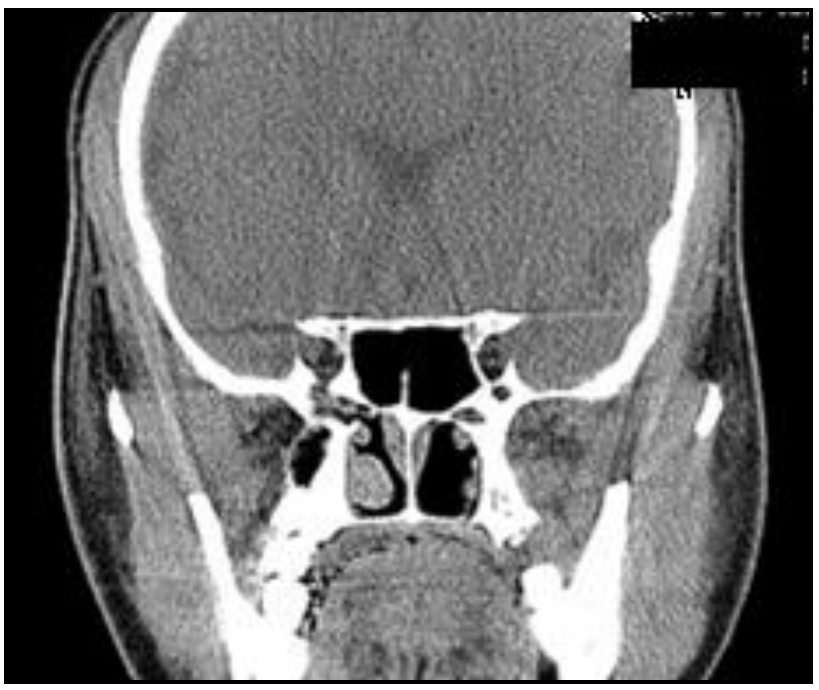

Figure 2. CT Scan showing a Single Incomplete Septum

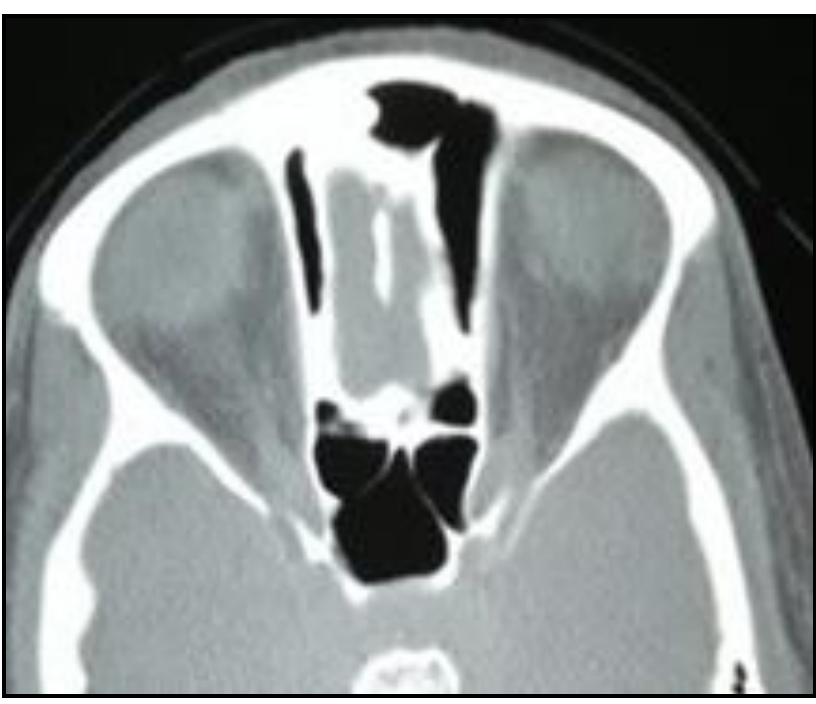

Figure 3. CT Scan showing Double Septum

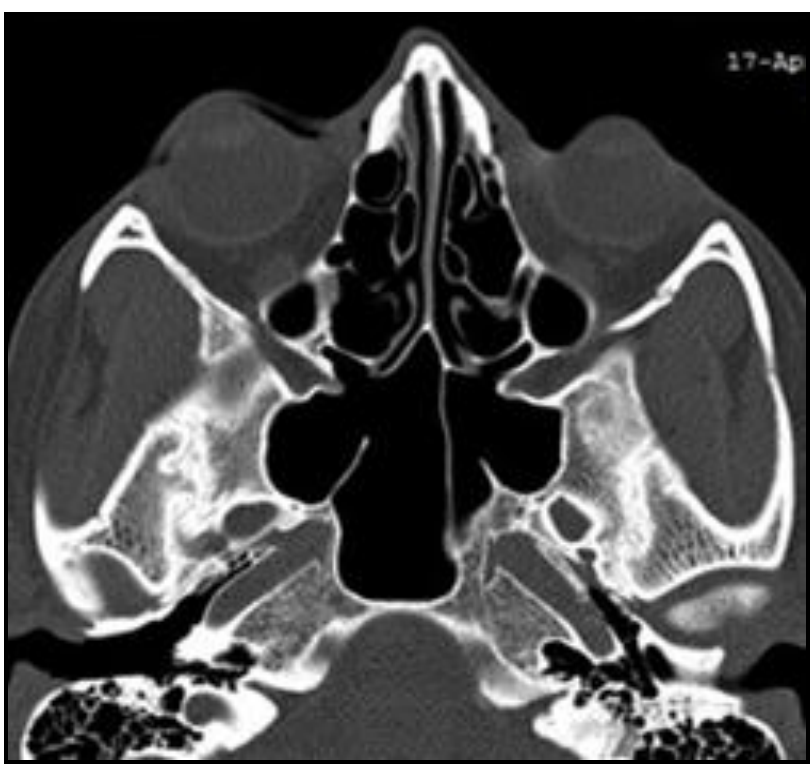

Figure 4. CT Scan showing Double Septum (One Complete and One Incomplete)

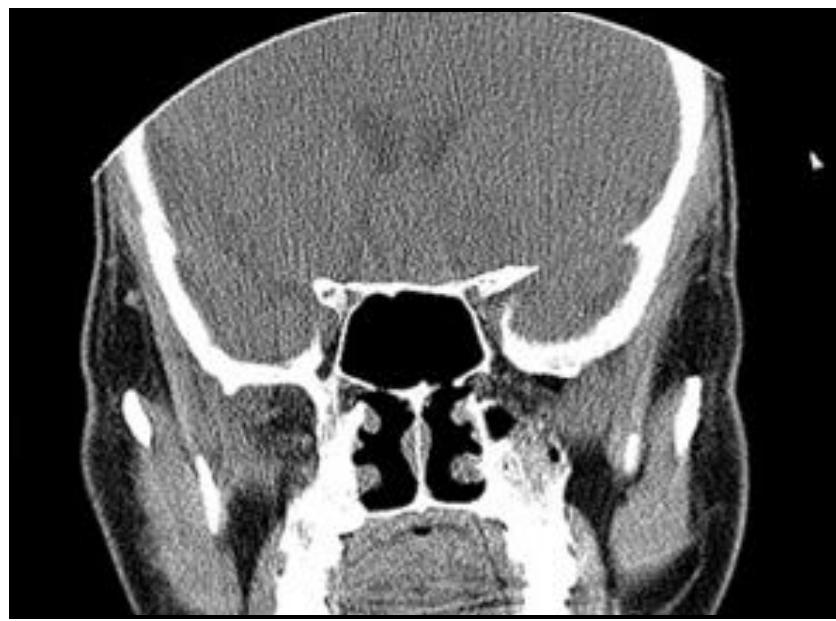

Figure 5. Aseptate Sphenoid

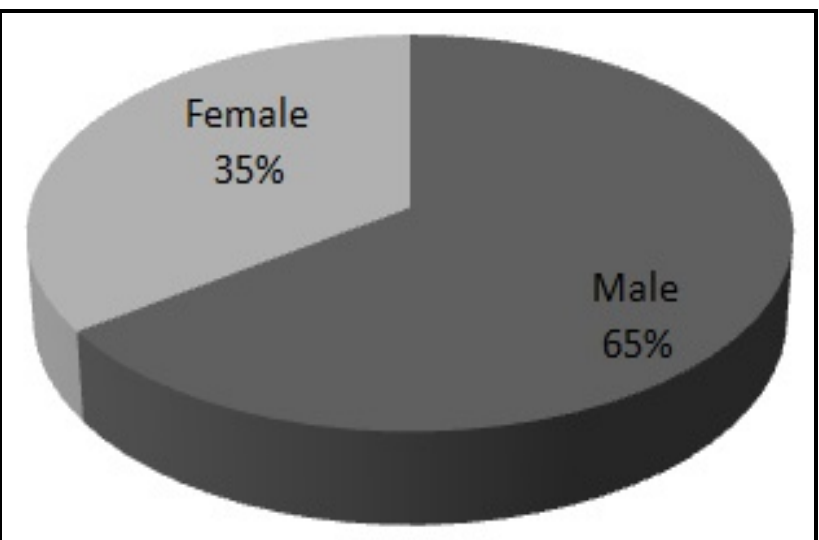

Figure 6. Sex Distribution of Patients

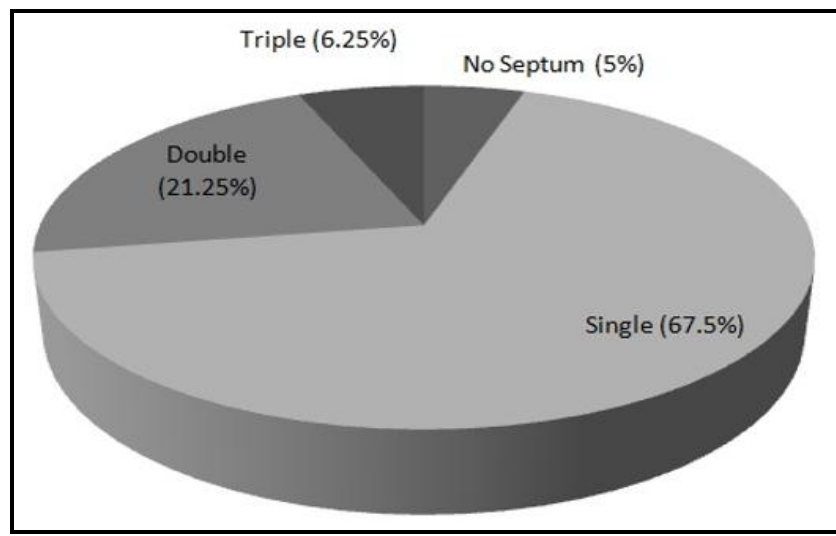

Figure 7. Pie Chart showing Various Findings in the Number of Septum

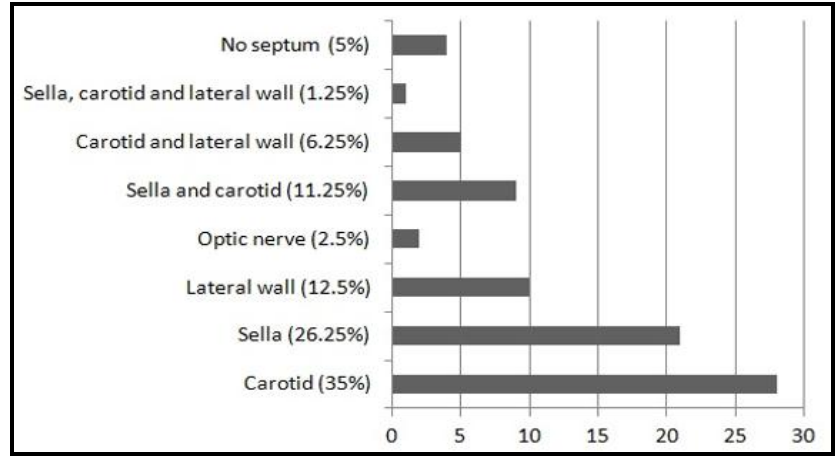

Figure 8. Bar Diagram showing Differences in the Variations in the Attachment of the Septum 


\section{DISCUSSION}

The detailed knowledge of anatomical variations of sphenoid sinus septum as well as its relationship with the surrounding structures like optic nerve, internal carotid artery, cavernous sinus and pituitary gland using computed tomography is paramount for endoscopic sinus surgery and endoscopic skull base surgery including trans-sphenoidal approach or para sellar area. It shortens the operation time, reduces the number of complications[10,11] as well as help in understanding the possible spread of any tumour or any inflammatory process in the sphenoid sinus and surrounding structures.[10] Higher number of anatomical variations of sphenoid sinus septum can lead to increased risk in terms of injury to important neurovascular and glandular structures. Here, we discuss the anatomical variation of sphenoidal sinus septum and its attachments to the projection of the internal carotid artery, optic nerve projection, sella turcica or directly to the lateral wall of the sphenoid sinus.

Usually, there is one intersphenoid septum which separates cavity of sphenoid sinus into two compartments. A study by Banna et al reported single septum (complete or incomplete) in $61 \%$ in [7]; $71 \%$ of cases in the study by Hamid et al,[8] whereas in the study by Idowu et al showed $95 \%$ of the cases having main single septum in the sphenoid sinus. We found single (complete or incomplete) in $67.5 \%$ of cases and in our study incidence of single septum is comparable to other study. Our study indicates that septa were mostly in paramedian position and more towards left side, but the study by Idowu et al[12] shows the septum is towards right side in most cases. Sareen et al[13] cited the existence of multiple septa in $80 \%$ of cases, Idowu et al[12] in $48.3 \%$ and a higher percentage $(95 \%)$ of multiple septa are registries in the study of Jaworeka et al[14] and $81.8 \%$ by Abdullah et al,[9] while Hamid et al[8] and Riza Dindar et al[15] cited the existence of $8.7 \%$ and $7.1 \%$ multiple septations respectively, whereas in our study we have found $21.25 \%$ of cases having double septa in the sphenoid sinus and triple septa of sphenoid is seen in $5 \%$ cases.

Chmielik et al[16] in their study in children with an average age of 10.9 years, cited the existence of the main septum in all cases. In similar studies conducted by Banna et al[7] and Hamid et al[8] found absent sphenoid septa in $11.4 \%$ and $10.8 \%$ cases respectively. Idowu et al[12] found lack of septum in only one case of a total of 60 analysed patients. In our study, we observed $5 \%$ of cases had no septum in sphenoid sinus.

It was stated by Idowu et al[12] that multiple accessory septa appear more frequently to the right of the main septum, both in men and women. They found that in men, 35 accessory septa were located to the right and 19 to the left side, while in women 18 to the right and 12 to the left of the main septum. But regardless of the existence of different percentages of multiple septa, all authors ${ }^{[17,18,19,20]}$ agree that it is the insertion of these septa to walls of sphenoid sinus is crucial for trans-sphenoidal surgery. Bademci and Ünal[4] evidenced septal insertion to carotid canal in $25.5 \%$ cases; Abdullah cites their presence in $12.9 \%$ cases and Hamid in $6.75 \%$ cases. We found insertion of main or accessory septa to carotid canal in 28 cases, which makes $35 \%$ of patients; 2 cases $(2.5 \%)$ to optic nerve projection; 21 cases $(26.25 \%)$ to sella turcica and carotid(s) in case of 9 patients $(11.25 \%)$; carotid(s) and lateral wall(s) in 5 patients (6.25\%) and only in 1 case to sella, carotid and lateral wall. Our study has the highest frequency where the septa gets attached to the carotid showing the risk of injury to the internal carotid artery during surgery.

Knowledge obtained from the previously available literature and from the results of our current study together insists that the sphenoidal main septum cannot be taken as a reliable landmark for endoscopic procedures. Its position, as we came to know from our study, is not always in the midline, but shifted to either right or to left side at least in parts of its entire length from anterior to posterior end. Also the frequency of insertion of the main and/or accessory sphenoid septa to the optic canal and the carotid canal varies significantly. Preoperative CT study of the PNS is necessary to avoid injury to the related structures.

\section{CONCLUSION}

In our data, sphenoid sinus has a lot of anatomical variations in terms of number and attachment to the related structures. So we must have the exact preoperative knowledge about the variations in the anatomy of the sphenoid septa for safe and successful surgery of sphenoid sinus and parasellar region. Hence, preoperative knowledge of anatomical variation of sphenoidal sinus septa by CT of paranasal sinuses is necessary to avoid intraoperative difficulties and complications.

\section{REFERENCES}

[1] Janq YJ, Kim SC. Pneumatization of the sphenoid sinus in children evaluated by magnetic resonance imaging. Am J Rhinology 2000;14(3):181-5.

[2] Szolar D, Preidler K, Ranner G, et al. The sphenoid sinus during childhood: establishment of normal developmental standards by MRI. Surg Radiol Anat 1994;16(2):193-8.

[3] Filho BC, Pinheiro-Neto CD, Weber R, et al. Sphenoid sinus symmetry and differences between sexes. Rhinology 2008;46(3):195-9.

[4] Norovaskuler PS, Onemi YBC. Surgical importance of neurovascular relationships of paranasal sinus region. Turkish Neurosurgery 2005;15(2):93-6.

[5] Sirikci A, Bayazit YA, Bayram M, et al. Variations of sphenoid and related structures. Eur Radiol 2000;10(5):844-8.

[6] Ünal B, Bademci G, Bilgili YK, et al. Risky anatomic variations of sphenoid sinus for surgery. Surgical and Radiologic Anatomy 2006;28(2):195-201.

[7] Banna M, Olutola PS. Patterns of pneumatisation and septation of the sphenoidal sinus. J Can Assoc Radiol 1983;34(4):291-3.

[8] Hamid O, El Fiky L, Hassan O, et al. Anatomic variation of the sphenoid sinus and their impact on transsphenoid pituitary surgery. Skull Base 2008;18(1):915.

[9] Abdullah BJ, Arasaratnam S, Kumar G, et al. The sphenoid sinuses: computed tomography assessment of septation, relationship to the internal carotid arteries, and side wall thickness in the Malaysian population. J HK Coll Radiol 2001;4:185-8.

[10] Shah NJ, Navnit M, Deopujari CE, et al. Endoscopic pituitary surgery: a beginner's guide. Indian J Otolaryngol H \& N Surg 2004;56(1):71-8. 
[11] Couldwell WT. Transsphenoidal and transcranial surgery for pituitary adenomas. J Neurooncol 2004;69(1-3):237-56.

[12] Idowu OE, Balogun BO, Okoli CA. Dimensions, septation, and pattern of pneumatization of the sphenoidal sinus. Folia Morphol (Warsz) 2009;68(4):228-32.

[13] Sareen D, Agarwal AK, Kaul JM, et al. Study of sphenoid sinus anatomy in relation to endoscopic surgery. Int J Morphol 2005;23(3):261-6.

[14] Jaworek JK, Troć P, Chrzan R, et al. Anatomic variations of the septation within the sphenoid sinus on CT scan images-an initial report. Przegl Lek 2010;67(4):279-83.

[15] Dundar R, Kulduk E, Soy FK, et al. Radiological evaluation of septal bone variations in the sphenoid sinus. Journal Medical Updates 2014;4(1):6-10.
[16] Chmielik A, Chmielik LP, Zabicka M, et al. Radiological diagnostics of the sphenoid sinus in children before pediatric endoscopic sinus surgery. Borgis-New Medicine 2009;4:92-4.

[17] Casiano RR. Anterior skull base resection. In: Endoscopic sinus surgery manual. Marel Dekker Inc, New York, 2002.

[18] Unlu A, Meco C, Ugur HC, et al. Endoscopic anatomy of sphenoid sinus for pituitary surgery. Clinical Anatomy 2008;21(7):627-32.

[19] Cavallo LM, Messina A, Cappabianca P, et al. Endoscopic endonasal surgery of the midline skull base: anatomical study and clinical considerations. Neurosurg Focus 2005;19(1):E2.

[20] Massoud A, Powell M, Williams R, et al. Transsphenoidal surgery for pituitary tumors. Arch Dis Child 1997;76(5):398-404. 